\title{
Influence of excitations originating from moving subway onto transferring vibrations from ground to structure
}

\author{
Krzysztof Kozioł 1,a \\ ${ }^{1}$ Cracow University of Technology, Cracow, Warszawska 24 St., 31-155, Poland
}

\begin{abstract}
In the majority of these influences parameters describing them are known. Nevertheless, in case of vibration it is not always simple to determine their parameters, especially when the source is located outside. The paper presents problems associated with the building loads generating by the subway passages. Subway train moving in a tunnel, through the layout of the track, transfers energy to the housing tunnel, then to the ground which then propagates in the ground layers to the building. This causes movement of foundations generating kinematic excitation for the entire facility. Generally way of propagation of vibration is complex. During designing new facility, it is possible - at its future location - to measure vibration level of existing sources on the ground. Soil movements in the vicinity of the foundation of the house are not the same - they are quite often very different from each other. This is related to wave transitions through the border between the different soil layers. Therefore there is a need to determine the transfer function between the vibrations registered on the soil and potential real construction loadings. Such analysis were made for an existing building with six floors loaded with excitations caused by movement of the subway in a nearby tunnel. According to Polish Standard [1] PN-85/B-02170 ("Hazard rating of vibrations transmitted through the ground to the buildings") only vibrations with frequency up to $100 \mathrm{~Hz}$ in terce octave bands $(1 / 3$ octave) were considered. As is apparent from the analysis the global amplitude value of vibrations registered on the ground is several times less than on the foundation of the building. However, in particular one-third octave bands (up to several $\mathrm{Hz}$ ) it may happen that the acceleration vibration of the foundation is higher than on the surrounding terrain. Increased amplitudes may be important in the effort analysis of structure cross-sections as well as the effects of vibrations on people staying inside. The issue of loading building with vibrations caused by the movement of subway should take into account an analysis of the nature of amplitude-frequency at the interface soil-foundation.
\end{abstract}

\section{Introduction}

Every structure is exposed to a variety of loadings having the "static" [2] or "dynamic" [1,3-6] character. Static loads as opposed to dynamic actions are quite well discerned, described and standardized. In case of dynamic loads, in particular those for whom excitation is not directly associated with the object, the route (path), must be considered in which vibrations are affecting the structure (Figure 1) [7-8].

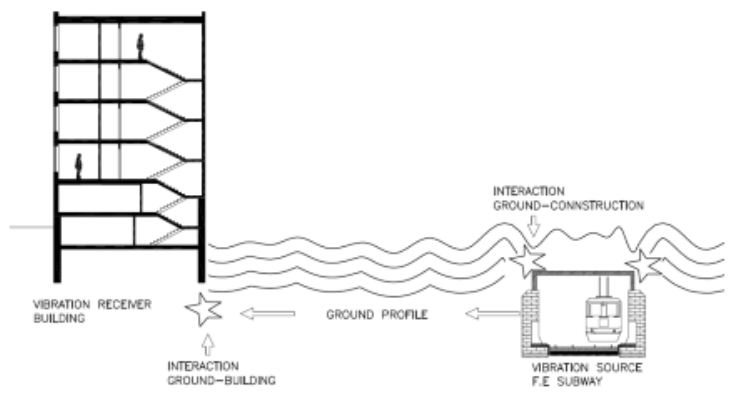

Figure 1 Way of vibrations propagation

During passage, subway transmits energy to the ground through the subgrade layers, from which energy propagates through the soils layer to the structure embedded in it causing movements of foundations, building and then the entire structure. It should be noted that the movement of the foundation and the soil located in the immediate vicinity are not the same, and quite often very different from each other. This issue is related to the wave transition through the various phases. The study presents the relationship between the load registered on the ground and fixed node structure located at its foundation level for building B (Figure 2).

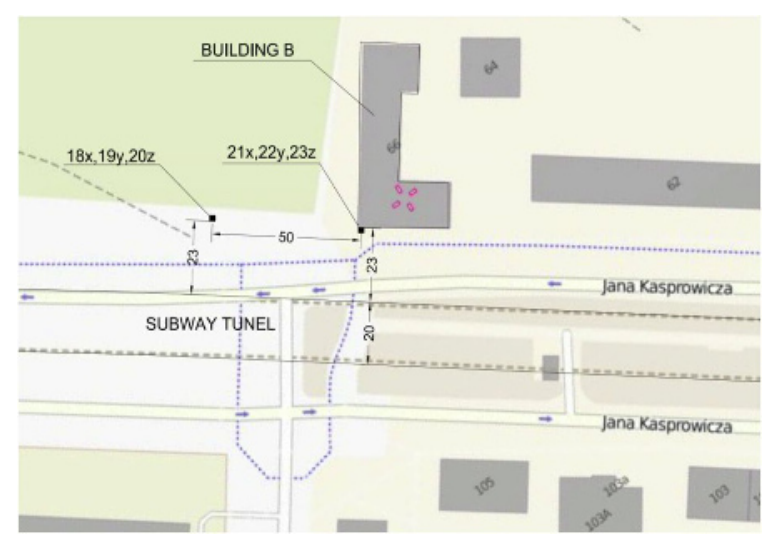

Figure 2 Building location

\footnotetext{
${ }^{\mathrm{a}}$ Corresponding author: kkoziol@pk.edu.pl
} 
Building B (Figure 3) it is six-storey structure with commercial units on the ground floor and living quarters on the top floor. It is made using traditional technology brick walls, ceilings constructed on steel beams, roof of wooden structure. The building is located $23 \mathrm{~m}$ horizontal and $14 \mathrm{~m}$ vertical far away from the nearest subway track.

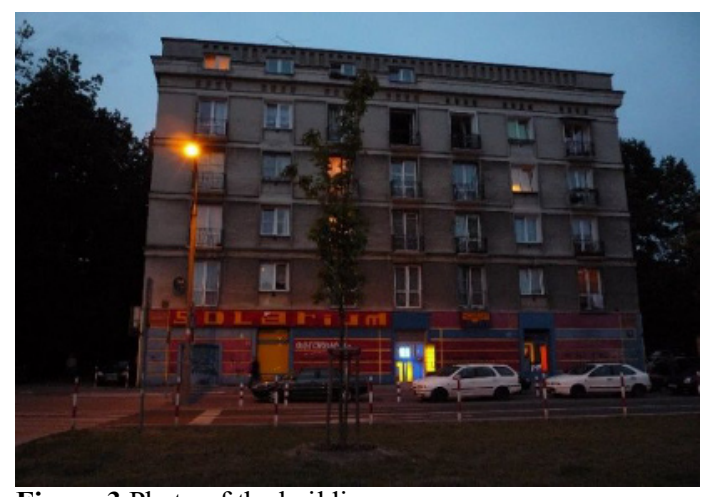

Figure 3 Photo of the building

Energy propagated in the ground has a wave character, so in order to avoid a possible interaction between the wave caused by subway and the reflected wave from the building the gauge located on the ground was shifted in relation to the building. In case of building B value of the sensors offset from the object was $50 \mathrm{~m}$ [8]. In order to measure acceleration, several gauges (accelerometers) were mounted on the building as well as on the ground. All measurements were carried out by the accredited Laboratory of Structural Strains and Vibrations located on Cracow University of Technology. This laboratory has a PCA accreditations. The study was performed in accordance with the following procedure:

- sensors calibration (PCB 393B12),

- installation of the sensors on the building (Figure 4, 5)

- installation and checking the measuring path,

- trial measurements in order to determine correct apparatus settings,

- performing the measurement - recording vibrations at the measurement points caused by individual events (subway rides and various vehicles) using LMS analyzer Scadas Mobile (16-channel version). Each event was written down in the measurement protocol,

- checking calibration after measurements,

- removal of the measurement path (after completion of all registrations).

Vibration measurements were made simultaneously in all measurement points located onto building.

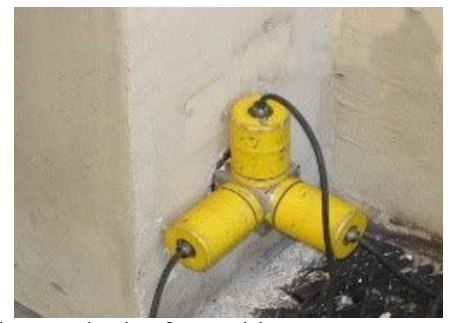

Figure 4 The method of attaching sensors to the structure (aluminum cube)
Gauges were attached to the building (Figure 4) using aluminum cube, rigidly glued to the corner of the building where two mutually perpendicular walls are facing - it allowed to neglect the impact of deformation of structural elements.

In case of sensors located on the ground, there was used special structure (Figure 5) in the form of a steel cross, attached to the ground by means of four ground anchors (bars $\phi 16$, length $25 \mathrm{~cm}$ ).

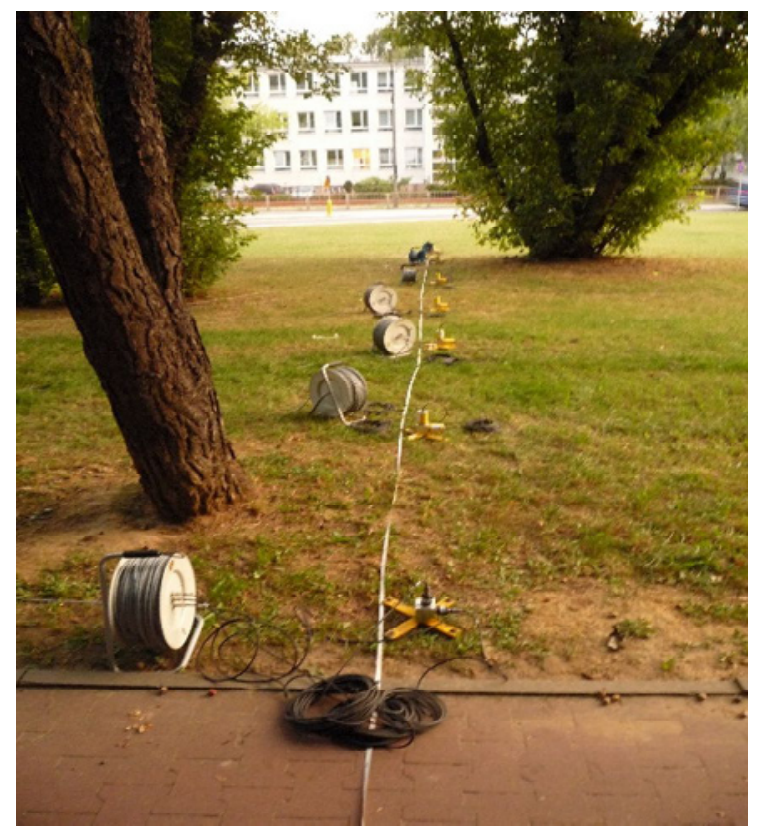

Figure 5 The method of attaching sensors onto ground (steel cross)

All measurements were performed using PCB Piezotronics accelerometers 393B12 type having sensitivity of $10 \mathrm{~V} / \mathrm{g}$. Registration was performed using LMS Scadas Mobile analyzer.

\section{Analysis}

As result of registration, there were obtained waveforms of acceleration vibrations recorded for ground and foundation of the building due to subways. In total, for building there were made 44 registrations in three directions: horizontal " $x$ " - parallel, " $y$ " - perpendicular and " $z$ "- vertical to the subway line.

Exemplary acceleration waveforms in the horizontal " $y$ " direction are visualized in Figs. 6 and 7. As shown in Figure 6 and 7 on the phases boundary (i.e. ground and structure), reduction of extreme values of vibration acceleration amplitude is observed. This paper attempts to identify quantitative (signal amplitude) and qualitative (signal frequency) change in the structure of recorded signal after passing between the phases.

Analysis of relationship between measured peak ground acceleration and acceleration of the building was presented in relation to size of the recorded ground acceleration next to the building. For this purpose, the dimensionless coefficient $\mathrm{P}$ was defined as the ratio of acceleration vibration of the building to ground acceleration. This ratio is non-linear (Figure 8), wherein 


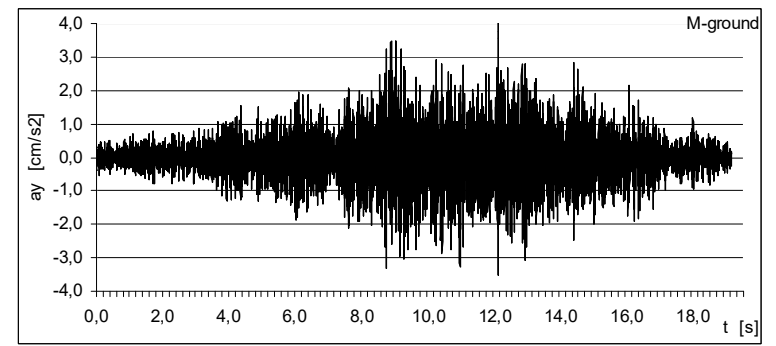

Figure 6 Horizontal (y-direction) ground acceleration

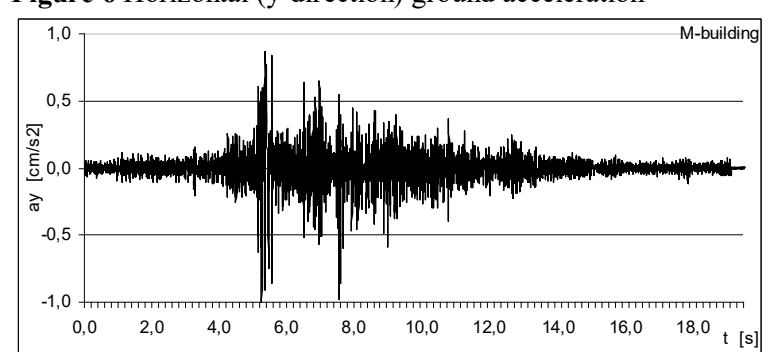

Figure 7 Horizontal (y-direction) acceleration of the building

the determination of fit coefficient of power curve is satisfactorily only for direction $\mathrm{z} \quad\left(\mathrm{R}^{2}=0.5547\right)$. In the horizontal direction determination of fit coefficient of power curve is unsatisfactory (it has value less than 0.5 ).
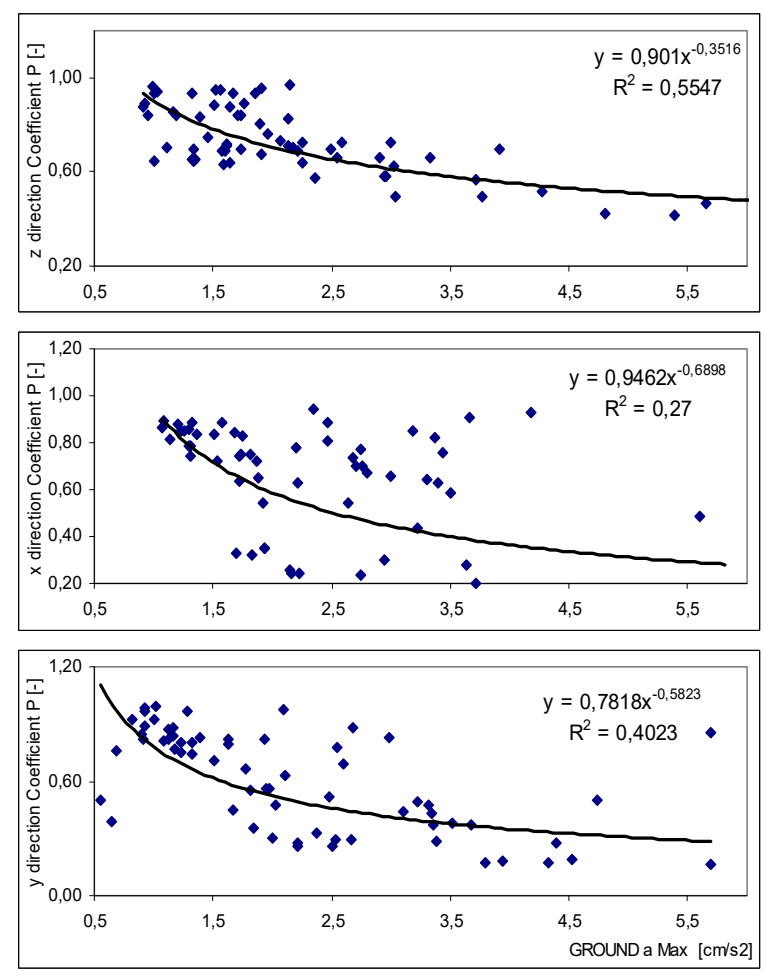

Figure 8. Change of the global maximum acceleration amplitude for the $\mathrm{z}, \mathrm{x} y$ directions

However, it should be noted, that in each of the analyzed vibration direction growth of the excitation (which representative is the signal recorded on the ground) the $\mathrm{P}$ ratio is lower for each of the analyzed direction. So then vibration with higher amplitudes are more reduced.It was decided to separate the response of the building and ground for $1 / 3$ octave band within range of the maximum amplitude in each one-third octave bands $[1,5,6]$. The value of this ratio (named $\mathrm{ZM}$ ) on $\mathrm{z}$, $\mathrm{x}$, $\mathrm{y}$ directions $\mathrm{z}, \mathrm{x}, \mathrm{y}$ in each one-third octave bands was shown in Figure 9 - maximum change of coefficient ZM and Figure 10 - arithmetic mean average of coefficient $\mathrm{ZM}$.

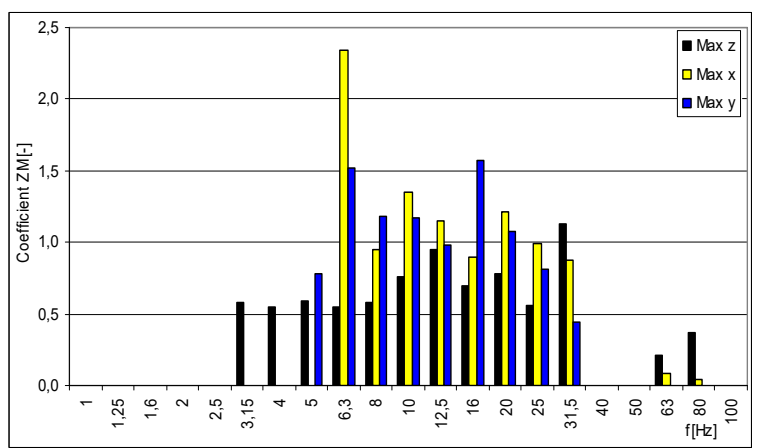

Figure 9. Maximum change of coefficient ZM factor depending on the center frequency band

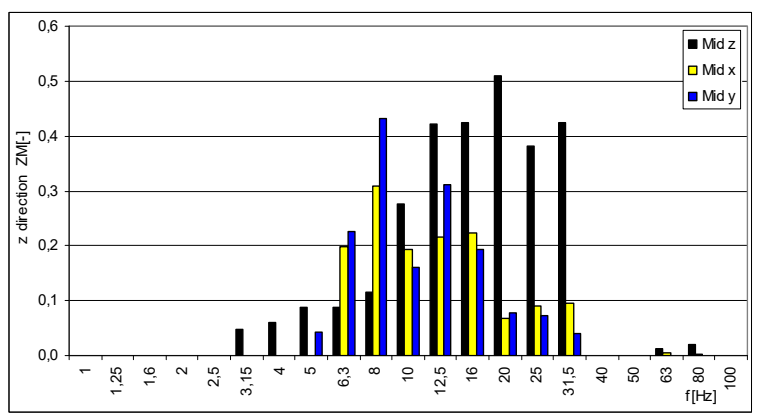

Figure 10. Arithmetic mean average of coefficient ZM factor depending on the center frequency band

\section{Conclusions}

Variation amount of the acceleration amplitude during transition from ground to building depends on excitation direction (subway location with respect to the object). Value of the global amplitude registered on the foundation of the building is lower than on the ground around it (Figure 8). Additionally it could be noted that the transfer ratio between ground and foundation of the analyzed object has a non-linear characteristics depending on the size of the acceleration amplitude of the ground. Nonlinearity coefficient increases with the amplitude of acceleration. Amplitude-frequency analysis (Fig. 10) show that the mean values of vibration acceleration of the building foundation are lower than the surrounding soil. As shown by the analysis of the test results it may happen that some of the components of acceleration of the foundation of the building (Figure 9) will be higher than the surrounding soil. For the considered building in case of horizontal direction within the range of $1 / 3$ octave center frequencies it is the range from $6.3 \mathrm{~Hz}$ to $20 \mathrm{~Hz}$. In contrast, for the vertical direction at a frequency $31,5 \mathrm{~Hz}$ it can be seen $10 \%$ amplitude greater than in case of the acceleration of the building foundation of the surrounding soil.

Table 1 shows the coefficients of the trend function defined as P (for global acceleration amplitude) and ZM coefficients (assumed as a power function $\left(y=\alpha^{*} a M a x^{\beta}\right)$ ) 
for individual center values of $1 / 3$ octave filters of the maximum amplitudes of the vibration signal depending on the frequency mid-band period. The last line in Table 1 refers to the extreme amplitudes that occurred in the recorded signal - $\mathrm{P}$ (Figure 8 ).

Table.1 Coefficients of the trend function for the transfer function between the ground and the foundation of the building accelerations vibration for the center frequency in the $1 / 3$ octave analysis

\begin{tabular}{|c|c|c|c|c|c|c|}
\hline \multirow{3}{*}{ f } & \multicolumn{6}{|c|}{ DIRECTION } \\
\hline & \multicolumn{2}{|c|}{$\mathbf{x}$} & \multicolumn{2}{|c|}{$y$} & \multicolumn{2}{|c|}{$\mathrm{z}$} \\
\hline & $\alpha$ & $\beta$ & $\alpha$ & $\beta$ & $\alpha$ & $\beta$ \\
\hline$[\mathrm{Hz}]$ & {$\left[\mathrm{s}^{*} \mathrm{~cm} / \mathrm{s}^{\mathrm{s}} 2\right]$} & H] & {$\left[\mathrm{s}^{*} \mathrm{~cm} / \mathrm{s}^{\wedge} 2\right]$} & {$[-]$} & {$\left[\mathrm{s}^{*} \mathrm{~cm} / \mathrm{s}^{\wedge} 2\right]$} & {$[-]$} \\
\hline 1 & 0,00 & $-1,01$ & 0,00 & $-0,77$ & 0,00 & $-0,91$ \\
\hline 1,25 & 0,00 & $-0,91$ & 0,00 & $-1,42$ & 0,00 & $-1,07$ \\
\hline 1,6 & 0,01 & $-0,62$ & 0,00 & $-1,44$ & 0,00 & $-0,70$ \\
\hline 2 & 0,12 & $-0,24$ & 0,01 & $-0,65$ & 0,00 & $-1,56$ \\
\hline 2,5 & 0,02 & $-0,50$ & 0,00 & $-1,01$ & 0,00 & $-1,14$ \\
\hline 3,15 & 0,00 & 0,40 & 0,02 & $-0,48$ & 0,00 & $-1,03$ \\
\hline 4 & 0,00 & $-0,75$ & 3,55 & 0,43 & 0,00 & $-0,79$ \\
\hline 5 & 0,04 & $-0,34$ & 1,10 & 0,26 & 0,01 & $-0,43$ \\
\hline 6,3 & 0,06 & $-0,32$ & 1,88 & 0,22 & 38,42 & 0,99 \\
\hline 8 & 0,32 & $-0,16$ & 0,00 & 1,30 & 0,67 & $-0,11$ \\
\hline 10 & 0,17 & $-0,32$ & 1,07 & 0,04 & 0,64 & $-0,11$ \\
\hline 12,5 & 0,03 & $-0,85$ & 0,45 & $-0,22$ & 0,70 & $-0,08$ \\
\hline 16 & 0,06 & $-0,83$ & 0,12 & $-0,61$ & 0,53 & $-0,19$ \\
\hline 20 & 1,19 & 0,15 & 6,57 & 0,64 & 0,64 & $-0,19$ \\
\hline 25 & 3,25 & 0,56 & 2,84 & 0,50 & 0,56 & $-0,17$ \\
\hline 31,5 & 0,32 & $-0,34$ & 0,67 & 0,06 & 0,53 & $-0,27$ \\
\hline 40 & 0,18 & $-0,27$ & 0,17 & $-0,12$ & 0,83 & $-0,09$ \\
\hline 50 & 0,17 & $-0,25$ & 0,09 & $-0,09$ & 0,65 & $-0,09$ \\
\hline 63 & 0,14 & 0,72 & 0,08 & 0,67 & 0,18 & $-1,42$ \\
\hline so & 0,06 & 0,73 & 0,05 & 1,53 & 0,26 & $-1,13$ \\
\hline 100 & 0,07 & $-2,00$ & 0,05 & $-2,32$ & 0,37 & $-0,79$ \\
\hline GLOB & 0,95 & $-0,69$ & 0,78 & $-0,58$ & 0,91 & $-0,35$ \\
\hline
\end{tabular}

Analysis of the slopes of the trend function $\mathrm{P}$ parameter revealed a large scatter, which depends on third-octave band center frequency (Figure 11-13).

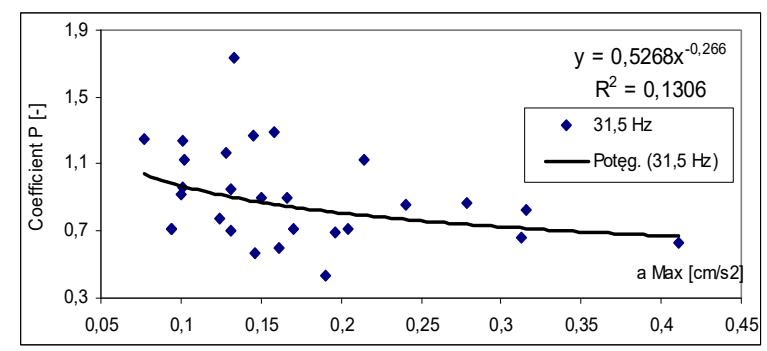

Figure 11 Change of the acceleration amplitude for the $31,6 \mathrm{~Hz}$ terce in the z-direction

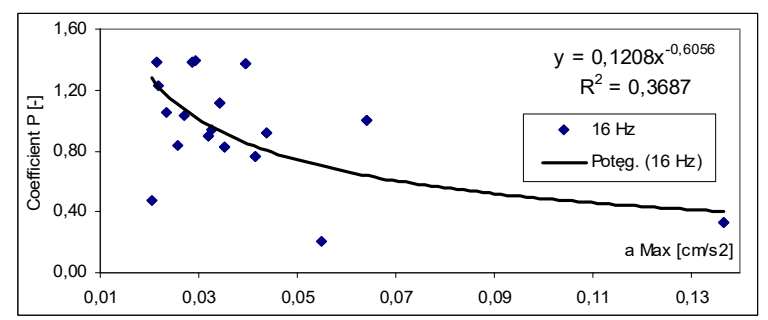

Figure 12 Change of the acceleration amplitude for the $16 \mathrm{~Hz}$ terce in the $y$-direction

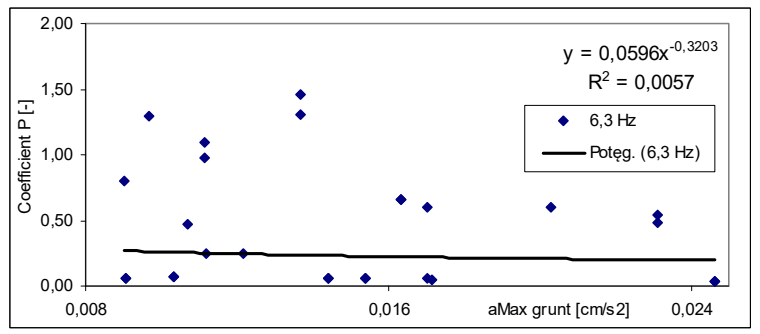

Figure 13 Change of the acceleration amplitude for the $6,3 \mathrm{~Hz}$ terce in the $\mathrm{x}$-direction

Due to the non-linear relationship between the size of the vibration acceleration amplitude change at the interface between ground and foundation of the building during determining the kinematic force coming from subway it is necessary to verify it experimentally. The parameter of this verification besides the vibration amplitude should be its frequency and direction of incoming wave - location of the subway in relation to the building.

\section{References}

1. PN-85/B-02170 (polish standard), Hazard rating of vibrations transmitted through the ground to the buildings

2. ISO 6897: Guidelines for the evaluation of the response of occupants of fixed structures, especially buildings and off-shore structures, to low frequency horizontal motion $(0,063$ to $1 \mathrm{~Hz})$, 1984, International Organization for Standardization

3. ISO 10131:2007, "Bases for design of structures Serviceability of buildings and walkways against vibrations"

4. BS 6472-1:2008, Guide to evaluation of human exposure to vibration in buildings, Part 1: Vibration sources other than blasting, 2008,

5. DIN 4150-3, Structural vibration, Part 3: Effects of vibration on structures

6. ISO 2631-2, Guide to the evaluation of human exposure to whole body vibration. Part 2- Vibration in buildings, 2003, International Organization for Standardization.

7. Kozioł K., Stypuła K.: Vibration measurements and computer simulations in the design of surface rail vibration isolation. Mat. VIII conf. Modern technologies and management systems for railways. Papers Scientific and Technical Association of Engineers and Technicians of Poland, Branch in Cracow, Zakopane 2-4.12.2009 r.

8. Stypula K., Koziol K.: Effects of changes to the track superstructure on human perception of rail-induced vibrations in a selected building near the rail tunnel in Warsaw - predictions and measurements. Proceedings of the 7th European Conference on Structural Dynamics, EURODYN 2008, 7-9 July 2008 Southampton, s. 58. 